\title{
TEORIA DA VIOLÊNCIA EM MARX
}

\author{
Mailson Bruno de Queiroz Carneiro Gonçalves ${ }^{1}$ \\ Eduardo Ferreira Chagas ${ }^{2}$
}

\begin{abstract}
Resumo:
O presente artigo tem como finalidade apresentar o conceito de violência em Marx a partir do $24^{\circ}$ capítulo do livro I de $O$ Capital, cujo cerne temático consiste no que o autor denomina de acumulação primitiva ou processo originário. Marx, ao apontar a diferença entre o valor produzido pelo trabalho e o salário pago ao trabalhador (mais valia) como base de exploração do sistema capitalista, procura compreender, através da história, a gênese do modo de produção capitalista e afirma que, ao contrário da hipótese defendida pela economia política clássica, a concentração de riqueza nunca foi resultado da negligência de muitos e da disposição de poucos, mas de um violento processo de expropriação camponesa, servidão da força de trabalho indígena, exploração da mão de obra africana e espoliação da América. Marx nega a base histórica do sistema capitalista proposta pelos teóricos liberais ao apontar um conjunto de fatores que contribuíram decisivamente para o surgimento do capitalismo na Europa, especialmente a Inglaterra, seu principal laboratório de estudos para a redação de $O$ Capital.
\end{abstract}

Palavras-chave: Marx; Violência; Gênese; Capital.

\section{TEORÍA DE LA VIOLENCIA EM MARX}

\section{Resumen:}

El presente artículo tiene como finalidad presentarles el concepto de violencia en Marx desde el capítulo 24 del libro I de El Capital, cuyo núcleo temático es lo que el autor llama de acumulación primitiva o proceso originario. Marx, tras señalar la diferencia entre valor producido por el trabajo y el salario pagado al trabajador como la base de explotación del sistema capitalista, trata de comprender, a través de la historia, la génesis del modo de producción capitalista y dice que, a diferencia de la hipótesis presentada por la economía política clásica, la concentración de la riqueza nunca ha sido el resultado de la negligencia de muchos y de la disposición de pocos, sino un proceso violento de despojo campesino, servidumbre de la fuerza de trabajo indígena, explotación de la mano de obra africana y saqueo de América. Marx niega la base histórica del sistema capitalista propuesta por los teóricos liberales y apunta una serie de factores que han contribuido decisivamente para el surgimiento del capitalismo en Europa, especialmente en Inglaterra, su principal laboratorio de estudios para la redacción de El Capital.

Palabras clave: Marx; Violencia; Génesis; Capital.

1 Possui graduação em Comunicação Social com habilitação em Jornalismo pela Universidade de Fortaleza/UNIFOR (2013). Bacharel em História pela Universidade Federal do Ceará/UFC (2017), graduando em Filosofia pela Universidade Estadual do Ceará/UECE (2017-2020), Mestre em Filosofia pela Universidade Federal do Ceará/UFC (2019). Doutorando em Filosofia pela Universidade Federal do Ceará/UFC (2020-2024). E-mail: bruno.qcg@ outlook.com.br.

2 Pós-Doctor em Filosofia pela Universität von Münster (Alemanha) (2019); Doutor em Filosofia pela Universität von Kassel (Alemanha) (2002); Mestrado em Filosofia pela Faculdade de Filosofia e Ciências Humanas (FAFICH) da Universidade Federal de Minas Gerais (UFMG, 1993); Graduado em Filosofia pela Universidade Estadual do Ceará (UECE, 1989). Professor Bolsista-Pesquisador do CNPq. É professor efetivo (associado) do Curso de Filosofia e do Programa de Pós-Graduação em Filosofia da Universidade Federal do Ceará (UFC) e Professor Colaborador do Programa de Pós-Graduação em Educação Brasileira da FACED - UFC. Atualmente, é pesquisador bolsista de produtividade CNPQ, é membro da Internationale Gesellschaft der Feuerbach- Forscher (Sociedade Internacional Feuerbach). E-mail: ef.chagas@uol.com.br. 
O conceito de violência em Marx é determinante para a construção de sua crítica à economia capitalista tendo em vista que a exploração do homem pelo homem lhe é irreversível. Para o autor, o capital - forma pela qual os homens produzem e distribuem sua riqueza material na modernidade - apresenta necessariamente, estruturalmente, a impossibilidade de emancipação social.

Quando Marx publicou o primeiro livro de O Capital (1867), trouxe junto à analise do seu objeto uma teoria da violência que lhe é constitutivo. Desde o primeiro capítulo, analisando a mercadoria, forma mais elementar e abstrata da riqueza em sociedades onde rege a produção capitalista, Marx demonstra que a reprodução do capital só pode existir pela exploração do trabalho.

A oposição imanente à essência da mercadoria entre valor de uso e valor bem como a dupla determinação do trabalho já indicam que a economia política tal como fora proposta por Smith e Ricardo traz de maneira inexorável uma contradição que só pode ser superada com a ruptura da própria ordem.

Assim, a revolução proletária seria uma forma de resistência capaz de decretar o colapso de um sistema que sobrevive por meio do trabalhador e não o reconhece, que se expande de maneira contínua e assim o empobrece, que cria um exército industrial de reserva que permanentemente o abastece.

De todo modo, este trabalho não tem como propósito extrair uma teoria da violência em Marx tendo o livro I de $O$ Capital como referência, mas apresentar de que maneira autor concebe a gênese do modo de produção capitalista baseado na leitura do $24^{\circ}$ capítulo da obra mencionada, intitulado $A$ assim chamada acumulação primitiva.

O autor, conforme aparece no início do próprio texto, pretende identificar o ponto de partida do capital tendo em vista que seu funcionamento já fora examinado anteriormente. Como veremos adiante, o declínio das relações feudais de produção, bem como, a expansão ultramarina europeia se constituiu, segundo Marx, nos grandes propulsores do capitalismo em sua fase embrionária, marcada fundamentalmente pela violência.

\begin{tabular}{|l|l|l|l|l|}
\hline Q Povista Dialectus & Ano 9 & n. 16 & Janeiro-Abril 2020 & p. $52-64$ \\
\hline
\end{tabular}


Marx (2013) apresenta o que seria a acumulação primitiva do capital na economia política clássica a partir de uma analogia com a tradição judaico-cristã. Segundo o autor, da mesma forma que as Escrituras trazem uma explicação para a degeneração do homem a partir da queda, os teóricos liberais procuram um fundamento idílico para a gênese do sistema capitalista. Se por um lado, a desobediência de Adão e Eva levou seu congênere ao estado de depravação, por outro a indolência de muitos e a diligência de poucos se transformaram historicamente no cerne da concentração de riqueza, mas o autor aponta uma distinção entre a mitologia bíblica e o discurso burguês no que diz respeito ao conceito de trabalho. Enquanto a teologia judaico-cristã diz que a subsistência do homem seria o resultado do esforço individual, os ideólogos do capitalismo elaboraram uma exceção a esse mandamento, contudo diz Marx (2013, p. 836):

É sabido o grande papel desempenhado na verdadeira história pela conquista, pela escravização, pela rapina e pelo assassinato, em suma, pela violência. Na suave economia política o idílio reina desde os primórdios. Desde o início da humanidade, o direito e o trabalho são os únicos meios de enriquecimento, excetuando-se naturalmente o ano corrente. $\mathrm{Na}$ realidade, os métodos da acumulação primitiva nada têm de idílicos.

Após afirmar que a gênese do capital se deve a uma história de violência marcada pelo domínio dos povos, pela espoliação e pelo genocídio, Marx (2013) prossegue sua análise declarando que o pressuposto à existência do capital bem como à sua reprodução é o afastamento entre trabalhadores e meios de produção ${ }^{3}$. Dessa maneira, a acumulação primitiva do capital se constituiria basicamente num processo que dissociou os produtores das condições necessárias à sua subsistência. Marx (2013, p. 836) observa que "a chamada acumulação primitiva é apenas o processo histórico que dissocia o trabalho dos meios de produção. É considerada primitiva porque constitui a pré-história do capital e do modo de produção capitalista". Em seguida, o autor afirma que a separação entre trabalhadores e meios de subsistência, condição básica para a gênese e o desenvolvimento do capitalismo, foi uma consequência

3 O paradoxo da noção de acumulação primitiva de capital consiste em que ela é uma acumulação de capital que se realiza sem o capital, é uma acumulação necessária para formar o capital. Diferente da noção de acumulação primitiva é a noção de acumulação de capital. Esta se realiza a partir da existência do capital e, por isso, o tem como pressuposto. A acumulação de capital se realiza convertendo o resultado do capital, a mais-valia, em novo capital, se realiza a partir, portanto de um capital já formado. A acumulação primitiva de capital é a acumulação necessária para formar o primeiro capital e não parte, portanto, de um capital já formado, mas, ao contrário, parte da inexistência do capital." (ANTUNES, 2005, p. 501).

\begin{tabular}{|c|c|c|c|c|}
\hline Rovita Q Dialectus & Ano 9 & n. 16 & Janeiro - Abril 2020 & p. $52-64$ \\
\hline
\end{tabular}


imediata das ruínas da sociedade feudal, mais precisamente de suas relações de produção. Marx (2013) ressalta que, embora os produtores tivessem se libertado das tarefas impostas pelos grandes proprietários de terra e das normas estabelecidas pelas corporações de ofício, seus meios de subsistência lhes foram tomados num processo de expropriação. $\mathrm{O}$ autor prossegue sua exposição afirmando que o triunfo do capital sobre o feudalismo e a hierarquia dos ofícios manteve a exploração do homem pelo homem, porém sob novos contornos.

Os capitalistas industriais, esses novos potentados, tiveram de remover os mestres das corporações e os senhores feudais, que possuíam o domínio dos mananciais das riquezas. Sob esse aspecto, representa-se sua ascensão como uma luta vitoriosa contra o poder feudal e seus privilégios revoltantes contra as corporações e os embaraços que elas criavam ao livre desenvolvimento da produção e à livre exploração do homem. (MARX, 2013, p. 837).

O autor dá continuidade à sua análise sobre a acumulação primitiva afirmando que as estruturas de poder existentes entre o assalariado e o capitalista na sociedade burguesa tem suas origens no julgo do trabalhador e destaca a mudança nas relações de exploração com o surgimento do capital. Assim, o conjunto de transformações históricas que contribuiu para o desenvolvimento de uma classe embrionária deve ser chamado de acumulação primitiva. Segundo Marx (2013), a maior expressão dessa metamorfose, cujas origens remontam ao início da Idade Moderna, é o deslocamento de trabalhadores rurais em direção às cidades com os cercamentos (enclosures), sobretudo no país que se tornaria o centro do capitalismo global: a Inglaterra ${ }^{4}$.

Marx (2013) assinala que as relações feudais de produção haviam praticamente desaparecido entre os ingleses no final do século XIV com o crescimento dos arrendatários livres, dos assalariados da agricultura e dos assalariados propriamente ditos, portanto ainda que a economia permanecesse essencialmente

4 De que forma se deu a expropriação na Inglaterra? Foi uma operação longa, demorada e violenta. Já na Idade Média, os senhores aboliram seus exércitos e dissolveram suas comitivas feudais por conta própria, e no começo do século XVII os governantes da Inglaterra fecharam publicamente os mosteiros, erradicaram frades, vendedores de indulgências e mendigos itinerantes, e destruíram o sistema medieval da caridade. Talvez o mais importante de tudo tenham sido as medidas tomadas pelos grandes latifundiários no fim do século XVI e começo do século XVII em reação a novas oportunidades do mercado. Elas alteraram radicalmente práticas agrícolas, cercando as terras, aráveis, despejando os pequenos proprietários e removendo locatários rurais, expulsando da terra milhares de homens e mulheres e negando-lhes acesso às áreas comunais. (LINEBAUGH e REDIKER, 2008, p. 27).

\begin{tabular}{|l|l|l|l|c|}
\hline Revista Dialectus & Ano 9 & n. 16 & Janeiro - Abril 2020 & p. $52-64$ \\
\hline
\end{tabular}


agrária, algumas mudanças no que diz respeito à produção e à distribuição da riqueza material ocorriam na Inglaterra durante a Baixa Idade Média.

O autor concebe o feudalismo como um modo de produção predominante medieval e fundamentado numa distribuição fundiária capaz de reunir o maior número possível de camponeses, portanto o poder da aristocracia rural não estaria baseado propriamente na grandeza de sua renda, mas na quantidade de trabalhadores produzindo em suas terras. Cumpre notar o que diz Marx a respeito do caso inglês, sua principal referência para os estudos sobre a economia capitalista ${ }^{5}$ :

Embora o solo inglês, depois da conquista normanda, se repartisse em baronias gigantescas, havendo casos de um só abranger 900 antigos senhorios anglo-saxônicos, estava ele coalhado de sítios dos camponeses, embora separados a espaços pelas grandes áreas senhoriais. (MARX, 2013, p. 839).

Marx (2013) afirma que essa forma de organização do trabalho bem como o crescimento das cidades durante a Baixa Idade Média garantiram aos europeus o acesso à riqueza conservando simultaneamente entraves que impediam o advento do capital, o que mudaria entre o final do século XV e o início do século XVI com o declínio das relações feudais de produção e o crescimento demográfico urbano, provocado sobretudo pela expropriação camponesa. No caso da Inglaterra, os grandes proprietários de terra haviam retirado dos trabalhadores o manso comunal ao transformar áreas de cultivo agrícola em pasto para a criação de ovelhas devido à demanda de um mercado em expansão pela manufatura têxtil. No mesmo sentido diz Marx (2013, p. 840): “O florescimento da manufatura de lã, com a elevação consequente dos preços da lã, impulsionou diretamente essas violências na Inglaterra".

O processo de cercamento das terras comunais também foi impulsionado pela reforma protestante, mais precisamente com a criação da Igreja Anglicana, tendo em vista a supressão das relações feudais de produção pela economia pastoril com a

5 As ideias de Marx sobre a revolução começaram com a análise da principal experiência revolucionária de sua época, a da França a partir de 1789. A França continuou a ser, pelo resto de sua vida, o exemplo "clássico" da luta de classes em sua forma revolucionária e o principal laboratório de experiência históricas em que se formaram a estratégia e as táticas revolucionárias. Contudo, a partir do momento em que ele entrou em contato com Engels, a experiência francesa foi suplementada pela experiência do movimento proletário de massa, de que a Grã-Bretanha, era então e continuou a ser, durante várias décadas, o único exemplo importante. (HOBSBAWM, 2011, p. 58-59).

\begin{tabular}{|l|l|l|l|l|}
\hline Q Povista Dialectus & Ano 9 & n. 16 & Janeiro-Abril 2020 & p. $52-64$ \\
\hline
\end{tabular}


expropriação e a doação de bens eclesiásticos a "vorazes favoritos da corte ou vendidos a preço ridículo a especuladores, agricultores ou burgueses, que expulsaram em massa os velhos moradores hereditários e fundiram seu sítios." conforme diz Marx (2014, p. 843).

$\mathrm{O}$ autor, depois de ter assinalado a transformação dos mansos comunais em áreas para a economia pastoril durante a Baixa Idade Média e o Início da Idade Moderna, observa que a expropriação camponesa seria amparada no século XVIII por um corpo de leis que assegurava a concentração fundiária e garantia o triunfo da aristocracia rural numa disputa contra o campesinato pelo controle da terra. Segundo Marx (2013, p. 846), “o progresso do século XVIII consiste em ter tornado a própria lei o veículo do roubo das terras pertencentes ao povo, embora os grandes arrendatários empregassem simultânea e independentemente seus pequenos métodos particulares. O conflito entre fazendeiros e camponeses pelo controle da terra era uma expressão da antítese entre o desenvolvimento do mercado e as normas do direito comum $^{6}$. Se, por um lado, a expansão do capitalismo era movida por interesses comerciais, por outro, as propriedades coletivas existiam para atender as necessidades dos produtores. O impacto da expropriação camponesa, em termos locais, pode ser resumido basicamente em três pontos: dissociação entre produtores e meios de subsistência, concentração fundiária e explosão demográfica nos grandes centros urbanos. Já no contexto das grandes navegações, o cercamento dos campos inseriu os trabalhadores na expansão ultramarina ao fomentar o deslocamento transatlântico dos expropriados em direção aos domínios coloniais ${ }^{7}$.

$\mathrm{O}$ autor conclui sua análise sobre as transformações que possibilitaram o advento do capitalismo na Inglaterra descrevendo novamente o processo de espoliação que marcou o início da Idade Moderna e substituiu estruturas de poder atreladas à ordem feudal pelo funcionamento arbitrário e contraditório do capital, revelando a insuficiência do discurso pautado numa riqueza oriunda do trabalho e de

6 Os historiadores têm observado que a grande era dos cercamentos parlamentares, entre 1760 e 1820 , comprova não só o frenesi pelo desenvolvimento agrícola, mas também a tenacidade com que sujeitos "impertinentes" e "despeitados" obstruíam os cercamentos por acordo, resistindo até o fim em favor da antiga economia baseada nos costumes. (THOMPSON, 1998, p. 95).

7 Essa emigração estava em sintonia com as teorias mercantilistas da época, que defendiam enfaticamente que os pobres fossem alocados em trabalhos úteis e produtivos e propugnavam a emigração, voluntária ou involuntária, como medida para reduzir o índice de pobres e encontrar ocupações mais rentáveis no exterior para os vagabundos e desocupados dos país. (WILLIAMS, 2013, p. 38).

\begin{tabular}{|l|l|l|l|l|}
\hline Q Povista Dialectus & Ano 9 & n. 16 & Janeiro-Abril 2020 & p. $52-64$ \\
\hline
\end{tabular}


princípios normativos, como aparece na economia política clássica. Marx (2013) reafirma que a ruptura das relações feudais de produção bem como o deslocamento em massa de camponeses em direção aos centros urbanos forneceram mão-de-obra necessária à engrenagem do capital, mas a demanda da indústria europeia no início da Idade Moderna era incapaz de absorver toda a força de trabalho disponível no mercado. Assim, as transformações econômicas impulsionadas pelo crescimento do comércio retiraram dos camponeses seus meios de subsistência sem deixar, a princípio, uma alternativa para sua reprodução material. Segundo ele, grande parte dos expropriados se enquadraria numa legislação de combate à vadiagem em virtude das próprias circunstâncias atreladas ao declínio do feudalismo, isto é, da falta de ocupação ocasionada pelos cercamentos. A primeira lei citada por Marx remonta ao século XVI, no decorrer da Dinastia Tudor, conforme segue abaixo:

\begin{abstract}
Henrique VIII, lei de 1530. - Mendigos velhos e incapacitados para trabalhar têm direito a uma licença para pedir esmolas. Os vagabundos sadios serão flagelados e encarcerados. Serão amarrados atrás de um carro e açoitados até que o sangue lhes corra pelo corpo; em seguida prestarão juramento de voltar à sua terra natal ou ao lugar onde moraram nos últimos 3 anos, "para se porem a trabalhar". Que ironia cruel! Essa lei é modificada, com acréscimos ainda mais inexoráveis, no ano 27 do reinado de Henrique VIII. Na primeira reincidência de vagabundagem, além da pena de flagelação, metade da orelha será cortada; na segunda, o culpado será enforcado como criminoso irrecuperável e inimigo da comunidade. (MARX, 2013, p. 856).
\end{abstract}

Mais adiante, o autor enumera outras medidas que previam uma série de penalidades contra os vadios na Inglaterra, durante os reinados de Eduardo VI, Elizabeth I e Jaime I, na França, sob o último dos capetos (Luís XVI), e nos Países Baixos, como Carlos V. Assim, Marx afirma que os camponeses foram duplamente afetados pela espoliação que prenunciava o capitalismo devido ao controle das terras comunais pelos latifundiários e ao conjunto de leis contra a vadiagem. O autor prossegue sua análise afirmando que a organização do trabalho numa sociedade burguesa é insuficiente para a expansão da economia capitalista tendo em vista que seu funcionamento pressupõe uma massa de trabalhadores disciplinados que aceitem as leis internas do capital devido ao crescimento populacional nas cidades e à formação de um exército de reservas. Segundo Marx (2013, p. 859), “a coação surda das relações econômicas consolida o domínio do capitalista sobre o trabalhador.

\begin{tabular}{|l|l|l|l|l|}
\hline Qevista Dialectus & Ano 9 & n. 16 & Janeiro-Abril 2020 & p. $52-64$ \\
\hline
\end{tabular}


Ainda se empregará a violência direta, à margem das leis econômicas, mas doravante apenas em caráter excepcional”.

O autor prossegue sua análise sobre a acumulação primitiva afirmando que a contradição entre trabalho e capital e a inexorável exploração do proletariado estavam atreladas diretamente às próprias condições de produção da economia capitalista, que por sua vez eram amparadas pelo Estado burguês. A classe que havia iniciado um processo de profundas transformações estruturais na Europa da Idade Moderna recebia apoio institucional para, segundo Marx (2013, p. 859), “'regular' o salário, isto é, comprimi-lo dentro dos limites convenientes à produção de mais-valia, para prolongar a jornada de trabalho e para manter o próprio trabalhador num grau adequado de dependência”. Desse modo, teríamos um elemento substancial para a gênese do capital.

A análise o autor sobre a gênese do modo de produção capitalista agora corresponde ao nexo entre a transformações materiais que ocorriam durante a Baixa Idade Média e o conjunto de leis que atendia as demandas de uma classe cuja riqueza pressupunha princípios normativos assimétricos. Cumpre notar o que diz Marx (2013, p. 860) sobre o impacto jurídico das novas relações de produção na Europa Ocidental já no século XIV:

\footnotetext{
Na Inglaterra, começa pelo "Estatuto dos Trabalhadores" de Eduardo III, de 1349, a legislação sobre trabalho assalariado, a qual desde a origem visa explorar o trabalhador e prossegue sempre hostil a ele. Na França, esse estatuto encontra seu correspondente na ordenança, publicada em nome do rei João. As legislações inglesa e francesa seguem os mesmos rumos e são idênticas em seu conteúdo.
}

Marx observa que o desenvolvimento da economia capitalista atuava como propulsor das mudanças normativas na Inglaterra durante a Idade Moderna e aponta alguns casos que corroboram sua tese, como uma fonte oficial do reinado de Elizabeth (Estatuto dos Aprendizes). De acordo com esse documento, o salário dos trabalhadores jamais poderia superar o limite previsto pela lei. Em caso de descumprimento, o empregador ficaria preso durante 10 dias enquanto ao trabalhador lhe seriam acrescentados mais 11 dias de detenção. Segundo Marx (2013, p. 861), “o Estatuto dos Aprendizes de Elizabeth (lei $\mathrm{n}^{\mathrm{o}} 3$ do ano 5 do seu reinado) autorizava os juízes de paz a fixar certos salários e modificá-los de acordo com as estações do ano e os preços das mercadorias", embora esse conjunto de medidas tenha se tornado

\begin{tabular}{|l|l|l|l|c|}
\hline Romita Dialectus & Ano 9 & n. 16 & Janeiro - Abril 2020 & p. $52-64$ \\
\hline
\end{tabular}


obsoleto com o crescimento demográfico nos principais centros industriais e a superexploração da força de trabalho. De acordo com Marx (2013, p. 861), "no período manufatureiro propriamente dito, o modo de produção capitalista estava suficientemente forte para dispensar, por impraticáveis e supérfluas, as leis reguladoras do salário". As determinações do Estado burguês para garantir o desenvolvimento da economia capitalista na esfera contratual eram análogas à legislação que proibia o funcionamento de organizações trabalhistas, pois, em ambos os casos, a finalidade dos princípios normativos era promover o avanço da industrialização com a inevitável exploração dos trabalhadores. Marx (2013, p. 862), sobre o caso inglês, assinala que:

As leis cruéis contra as coligações dos trabalhadores foram abolidas em 1825 ante a atitude ameaçadora do proletariado. Mas, apenas em parte. Alguns belos resíduos dos velhos estatutos só desapareceram em 1859. Finalmente, a lei do Parlamento, de 29 de junho de 1871, pretendeu eliminar os últimos vestígios dessa legislação de classe com reconhecimento das Trades`Union. Mas uma lei do Parlamento, da mesma data (destinada a modificar a legislação criminal na parte relativa a violências, ameaças e ofensas), restabelece na realidade a situação anterior sob nova forma.

Marx, analisando os desdobramentos normativos da Revolução Francesa, compreende a Lei de Le Chapelier como uma expressão da luta de classes após a queda do Antigo Regime e a ascensão da burguesia. Cumpre notar o que diz o autor sobre o decreto que proibiu a organização sindical na França num momento de instabilidade política com o surgimento de uma nova ordem.

\footnotetext{
Logo no começo da tormenta revolucionária, a burguesia francesa teve a audácia de abolir os direitos de associação dos trabalhadores, que acabara de ser conquistado. Com o decreto de 14 de junho de 1791, declarou toda coligação dos trabalhadores um "atentado à liberdade e à declaração dos direitos do homem", a ser punido com a multa de 500 francos e a privação de direitos de cidadania por 1 ano. Essa lei que, por meio da coação policial, comprime a competição entre o capital e o trabalho dentro de limites convenientes ao capital e sobreviveu a revoluções e a mudanças de dinastias. (MARX, 2013, p. 863).
}

Dessa maneira, o autor ressalta, com base em experiências históricas na Europa Ocidental, o papel indispensável do Estado no processo de acumulação primitiva do capitalismo bem como na consolidação da economia burguesa, portanto a gênese e a expansão do capital são expressões de uma antítese marcada pela

\begin{tabular}{|l|l|l|l|l|}
\hline Q Revista Dialectus & Ano 9 & n. 16 & Janeiro-Abril 2020 & p. 52 - 64 \\
\hline
\end{tabular}


violência cujo pressuposto normativo é a superestrutura jurídica. Após demonstrar como as relações feudais de produção entraram em declínio com a efervescência comercial e o desenvolvimento de uma economia monetária, situar historicamente a metamorfose que converteu uma massa de trabalhadores em assalariados e desvelar a importância do Estado para a burguesia, Marx descreve o processo que culminou na transformação de agricultores em arrendatários e destaca a importância da expropriação camponesa para o advento do capital no campo. Cumpre notar o que diz o autor:

\begin{abstract}
$\mathrm{Na}$ Inglaterra, o ponto de partida das transformações que culminam com o aparecimento da figura do arrendatário capitalista, seu germe mais primitivo, é o bailiff, ainda servo. Sua posição é análoga à do villicus da velha Roma, embora com uma esfera menor de atribuições. Durante a segunda metade do século XIV, é substituído por um colono a quem o landlord fornece sementes, gado e instrumentos agrícolas. Sua situação não é muito diferente da do camponês. Apenas explora mais trabalho assalariado. Logo se torna parceiro, um tipo que se parece mais com o verdadeiro arrendatário. $\mathrm{O}$ parceiro fornece uma parte do capital, o landlord a outra. Ambos dividem o produto total em proporção contratualmente estabelecida. Essa forma desaparece rapidamente na Inglaterra para dar lugar ao arrendatário propriamente dito, que procura expandir seu próprio capital empregando trabalhadores assalariados e entrega ao landlord uma parte do produto excedente em dinheiro ou em produtos, como renda da terra. (MARX, 2013, p. 864).
\end{abstract}

Após ter demonstrado historicamente como o camponês se transformou em arrendatário na Inglaterra, Marx enumera os fatores que possibilitaram o desenvolvimento do capital agrário, como a revolução nas técnicas de cultivo da terra, a expropriação camponesa, a extensão dos contratos com a aristocracia feudal, a desvalorização dos metais preciosos e a redução dos salários reais. Além disso, o autor assinala que a plena expansão do comércio de gêneros agrícolas e as garantias contratuais, como a renda fixa paga ao latifundiário pelo uso da terra, aumentaram o capital dos arrendatários sem que eles tivessem necessariamente projetado formas de multiplicar seus ganhos. Assim, todas as condições para o fortalecimento da economia capitalista em áreas rurais estavam presentes na Inglaterra durante o início da Idade Moderna. O impacto das transformações no sistema de produção em áreas rurais, como a mudança no regime de propriedade e o desenvolvimento das técnicas agrícolas, reside não só na formação de um exército industrial de reserva nos grandes centros urbanos, mas também no surgimento de um mercado interno para a economia capitalista. Segundo Marx (2013, p. 868-869), “a expropriação e a expulsão de uma

\begin{tabular}{|l|l|l|l|l|}
\hline Q & Anovista 9 & n. 16 & Janeiro-Abril 2020 & p. $52-64$ \\
\hline
\end{tabular}


parte da população rural liberam trabalhadores, seus meios de subsistência e seus meios de trabalho, em benefício do capitalista industrial; além disso, cria o mercado interno". Dessa forma, o autor assinala que a dissociação entre produtores e meios de subsistência foi determinante para fortalecer o consumo a partir da troca mediada pelo equivalente universal, isto é, o dinheiro, tendo em vista que a riqueza produzida pela sociedade burguesa se converte necessariamente em mercadoria. Assim, o trabalhador se tornou inevitavelmente consumidor da grande indústria e fonte de capital variável enquanto o conjunto dos meios de produção passou a ser capital constante. Cumpre notar o exemplo dado pelo autor para elucidar sua análise:

Imaginemos que uma parte dos camponeses da Westfalia que, no tempo de Frederico II, fiavam todo o linho que produziam, fosse violentamente expropriada e expulsa de suas terras, sendo os restantes que lá ficassem transformados em jornaleiros de grandes arrendatários. Suponhamos ainda que se construam grandes fiações e tecelagens, onde esses expropriados passem a trabalhar como assalariados. O linho não mudou materialmente em nada. Não se modificou nenhuma de suas fibras, mas uma nova alma social entrou no seu corpo. Constitui agora parte do capital constante do padrão manufatureiro. Antes, repartia-se entre os inumeráveis pequenos produtores que o cultivavam e fiavam em pequenas porções com suas famílias; agora, concentram-se nas mãos de um capitalista para quem outras pessoas o fiam e tecem. (MARX, 2013, p. 867).

Após ter examinado as condições que possibilitaram a gênese do arrendatário e o crescimento da agricultura comercial na Inglaterra, Marx (2013) procura demonstrar como o processo de industrialização avançou durante a Idade Moderna a ponto de transformar a burguesia numa classe com interesses claros e coesos. Segundo o autor, o modo de produção capitalista, cuja expressão encontra-se na fórmula D-M-D', ainda enfrentava obstáculos no decorrer das grandes navegações tendo em vista as demandas do mercado mundial e sua relação com o colonialismo. De todo modo, Marx (2013, p. 872) destaca a importância da expansão ultramarina para a acumulação primitiva do capital afirmando que:

As descobertas de ouro e de prata na América, o extermínio, a escravização das populações indígenas, forçadas a trabalhar no interior das minas, o início da conquista e pilhagem das Índias Orientais e a transformação da África num vasto campo de caçada lucrativa são os acontecimentos que marcam os albores da era da produção capitalista.

Marx (2013) observa que esses métodos de violência se transformaram em propulsores do comércio e da navegação na Europa, garantindo a concentração de

\begin{tabular}{|l|l|l|l|l|}
\hline Q Povista Zialectus & Ano 9 & n. 16 & Janeiro-Abril 2020 & p. $52-64$ \\
\hline
\end{tabular}


capital necessária ao processo de industrialização subsequente, portanto ainda que os entraves dos Estados absolutistas impossibilitassem o pleno desenvolvimento do sistema capitalista após o declínio das relações feudais de produção, o conjunto de práticas econômicas adotado pelas monarquias nacionais forneceu a posteriori as condições materiais para o crescimento da atividade industrial. Refletindo especialmente sobre o colonialismo, Marx (2013, p. 875) assinala que: "As colônias asseguravam mercado às manufaturas em expansão e, graças ao monopólio, uma acumulação acelerada. As riquezas apressadas fora da Europa pela pilhagem, escravização e massacre refluíam para a metrópole onde se transformavam em capital”.

Desse modo, podemos afirmar que a gênese do capitalismo na Europa Ocidental, sobretudo na Inglaterra, foi marcada por um violento processo de expropriação camponesa que anunciava progressivamente o fim das relações feudais de produção bem como o alvorecer de uma economia cujo desenvolvimento estava sujeito à expansão ultramarina, tendo em vista que o regime de exclusividade comercial, a exploração da força de trabalho indígena na América e o tráfico internacional de escravos eram suas forças constitutivas.

A acumulação primitiva, situada entre o final da Baixa Idade Média e o início da Idade Moderna, foi indispensável ao surgimento do capitalismo na Europa Ocidental tendo em vista que o declínio das relações feudais de produção, a espoliação da América, a servidão indígena e a exploração da mão de obra africana forneceram a base material necessária a uma nova ordem econômica.

O processo originário constitui-se numa análise histórica da economia capitalista devido à tentativa do autor de compreender o processo que culminou no advento de novas relações de produção no continente europeu, principalmente na Inglaterra, seu principal laboratório de estudos no que diz respeito à economia política.

O objetivo desse trabalho foi apresentar o conceito de violência em Marx a partir do $24^{\circ}$ capítulo do livro I de O Capital, intitulado A Assim Chamada Acumulação Primitiva, porém o autor demonstra em sua crítica ao sistema capitalista, apresentada permanentemente em seu legado teórico, que a gênese, a reprodução e a mundialização da economia capitalista só foram possíveis através da violência.

\begin{tabular}{|l|l|l|l|l|}
\hline Q & Anovista 9 & n. 16 & Janeiro - Abril 2020 & p. $52-64$ \\
\hline
\end{tabular}


O autor observa que seu processo originário dissociou os produtores das condições necessárias à sua subsistência e saqueou o mundo colonial, seu desenvolvimento, cuja expressão encontra-se na fórmula D-M-D', aniquilou o espírito do proletariado e o empobreceu devido à exploração do trabalho ${ }^{8}$ e sua expansão global aniquilou a autodeterminação dos povos ${ }^{9}$.

\section{REFERÊNCIAS}

ANTUNES, Jadir. Da possibilidade à realidade: o desenvolvimento dialético das crises em O Capital de Marx. Campinas: Unicamp/IFCH (Tese de Doutoramento em Filosofia), 2005.

HOBSBAWM, Eric. Como mudar o mundo: Marx e o marxismo, 1840-2011. São Paulo: Companhia das Letras, 2011.

LINEBAUGH, Peter; REDIKER, Marcus. A hidra de muitas cabeças: marinheiro, escravos, plebeus e a história oculta do Atlântico. São Paulo: Companhia das Letras, 2008.

MARX, KARL. O Capital: crítica da economia política. Livro I, volume II. Rio de Janeiro: Civilização Brasileira, 2014.

THOMPSON, Edward. Costumes em comum: estudos sobre a cultura popular tradicional. São Paulo: Companhia das Letras, 1998.

WILlIAMS, Eric. Capitalismo e Escravidão. São Paulo: Companhia das Letras, 2013.

8 Ver o texto de Marx contido nos Manuscritos Econômico-Filosóficos (1844), intitulado Trabalho estranhado.

9 Ver o artigo de Marx publicado em 1853 no jornal americano New-York Daily Tribune, intitulado A dominação britânica na Índia.

\begin{tabular}{|l|c|c|c|c|}
\hline Revista Dialectus & Ano 9 & n. 16 & Janeiro - Abril 2020 & p. $52-64$ \\
\hline
\end{tabular}

